\title{
FINITE ELEMENT ANALYSIS OF ALUMINIUM ALLOYS FOR THEIR VIBRATION CHARACTERISTICS
}

\author{
Vinay V. Kuppast ${ }^{1}$, Vijay Kumar N. Chalwa ${ }^{2}$, S. N. Kurbet ${ }^{3}$, Aravind M. Yadawad ${ }^{4}$ \\ ${ }^{I}$ Department of Mechanical Engineering, Basaveshwar Engineering College, Bagalkot 587102, Karnataka, India \\ ${ }^{2} R \& D$ Dean, Department of Mechanical Engineering, SMSMPITR, Akluj \\ ${ }^{3}$ Department of Mechanical Engineering, Basaveshwar Engineering College, Bagalkot 587102, Karnataka, India \\ ${ }^{4}$ Department of Mechanical Engineering, the National Institute of Engineering Mysore, India
}

\begin{abstract}
Aluminium alloys are being extensively used in many applications due to their excellent weight to strength properties. Many research works have been carried out to study and improve the mechanical properties of aluminium alloys. The composition of alloying elements plays an important role in deciding the properties of an alloy. The results of numerical methods have been accepted widely as they closely match with the experimental results. In the present study a numerical analysis tool i.e., finite element analysis (FEA) is used. The work presented in this paper is aimed at the study of effect of vibration characteristics of aluminium alloys of different compositions. The modeling and analysis is carried out using ANSYS software. A modal analysis is carried out to understand the vibration behavior i.e., natural frequency and mode shapes, of the material considered. The mode shapes and natural frequency play an important role in the design of dynamic machines. The harmonic analysis has been made to determine frequency characteristics. The analysis program reads the data from the input file processes the data and creates the output file containing the nodal displacements and nodal stress values of different stresses.
\end{abstract}

From the analysis it is concluded that as the copper and silicon content in the alloys increases deformation decreases inversely. ANSYS results confirm the least deformation in case of 380 alloys. Young's Modulus and the ultimate tensile strength of the 380 alloys increase with the increase in copper and silicon content. Hence Al 380 alloys exhibit good strength with minimum vibration.

Keywords: Aluminium alloys, vibration characteristics, FEA

\section{ALUMINUM AND ITS ALLOYS [1].}

Since the specific gravity of Aluminium is approximately 2.7 $\mathrm{g} / \mathrm{cc}$, the composites of Aluminium play a very significant role in light weight machine components. Silicon, copper, magnesium, iron, manganese, and zinc are important elements in Aluminium composites. The properties of these alloys can be prepared and these readily can be used in design engineering with the instructions for other alloys.

\section{ALUMINIUM ALLOYS FOR DIFFERENT INDUSTRIAL APPLICATIONS}

Aluminium alloys can be used for many applications in manufacturing industries. The some important properties have been listed as; non heat treatable, good hardness, corrosion resistance, very good ductility, lightweight, high strength, high ratio of strength to weight, corrosion resistance, flexibility and resilience, good electrical and thermal conductivity.

\section{SELECTING ALUMINUM ALLOYS. [2]}

It may be specified for most product applications. Some of the uses of this alloy include electronic and communications equipment, automotive components, engine brackets, transmission and gear cases, appliances, lawn mower housings, furniture components, hand and power tools.

Alloy 390 (ANSI/AA B390.0) is used for die cast valve bodies and compressor housings in pistons. Alloy AZ91D is a highpurity alloy with excellent corrosion resistance, excellent cast ability, and excellent strength. Corrosion resistance is achieved by enforcing strict limits on three metallic impurities: iron, copper and nickel. Ductility increases at the expense of cast ability and strength, as aluminum content decreases. Therefore, the alloy with the highest aluminum content that will meet the application requirements should be chosen. The alloying elements are shown in Table 1. 
Table 1 Element used In Al Alloy. [5] [10]

\begin{tabular}{|l|l|}
\hline $\begin{array}{l}\text { Element used in } \mathrm{Al} \\
\text { alloy }\end{array}$ & $\begin{array}{l}\text { Properties } \\
\text { Copper, } \mathrm{Cu} \\
\text { but reduces ductility. its content does } \\
\text { not exceed 9\% }\end{array}$ \\
\hline Silicon, Si & $\begin{array}{l}\text { Gives low shrinkage value, casting } \\
\text { fluidity, clean sharp castings ,good } \\
\text { ductility, better resistance to corrosion, } \\
\text { good mechanical properties used } \\
\text { from8-14\% }\end{array}$ \\
\hline Manganese, MN & $\begin{array}{l}\text { Improves resistance to corrosion and } \\
\text { renders metal readily weld able. added } \\
\text { up to 1.5\% }\end{array}$ \\
\hline 4.Aluminium,Al & $\begin{array}{l}\text { Light in weight and gives equal strength } \\
\text { to steel when alloyed in proper } \\
\text { proportions. }\end{array}$ \\
\hline
\end{tabular}

\section{LITERATURE SURVEY}

Guo-cong li [6] presented on damping capacity of a wide range of engineering metals which has been determined at direct cyclic stresses up to the fatigue limit. R.D.Adams [7] presented damping capacity of high strengthdampingaluminumalloysprepared by rapid solidification and powder metallurgy process. Showed the damping is a useful parameter for controlling vibration and movement in the design of the structure (Hazrati Niyari [10]). Yijie Zhang [11] discussed the effect of $\mathrm{Ti}$ and $\mathrm{Mg}$ on the damping behavior of aluminum composites.

\section{TEST SPECIMEN}

The test specimen, modelled on micro mechanical scale, used for the simulation work is shown in Figure 1 and the dimensions of which are, length of $100 \mu \mathrm{m}$, breadth of $200 \mu \mathrm{m}$ and thickness of $20 \mu \mathrm{m}$.

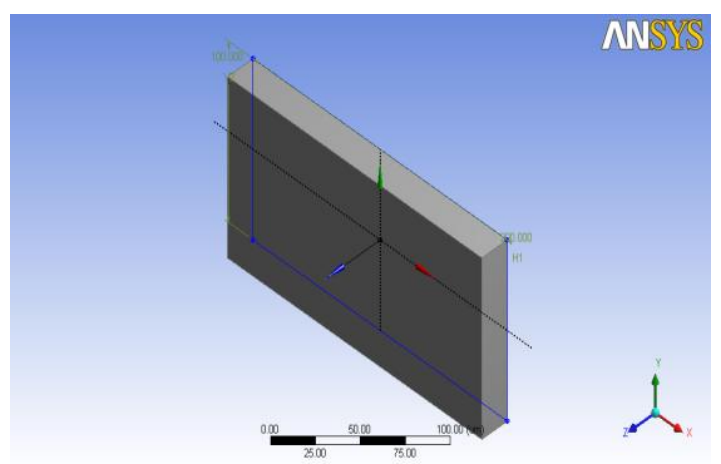

Fig 1 Schematic of the experimental specimen

\section{FINITE ELEMENT ANALYSIS. [4]}

FEA is a technique that discretizes a given physical or mathematical problem into smaller fundamental parts called elements. A solution to the problem as a whole is obtained by assembling the individual solutions of the elements. Complex problems can be tackled by dividing the problem into smaller and simpler problems that can be solved using existing mathematical tools. Displacements are related to the external loads through a mathematical relationship of the form:

$$
[K]\{Q\}=\{F\}
$$

Where $\mathrm{K}$ is the stiffness matrix, $\mathrm{Q}$ is the vector of nodal degree of freedom, and $\mathrm{F}$ is the vector of nodal forces.

\section{BOUNDARY CONDITIONS}

The load and displacement boundary condition applied for the investigations are as; left edge of the model is constrained that is nodes lying on $\mathrm{Y}$ axis are constrained for all degrees of freedom. The nodes lying on top and bottom edge of the model are free. And on the right edge of the model a load of $10000 \mu \mathrm{N}$ is applied.

\section{RESULTS \& DISCUSSION.}

\subsection{Modal Analysis. [3]}

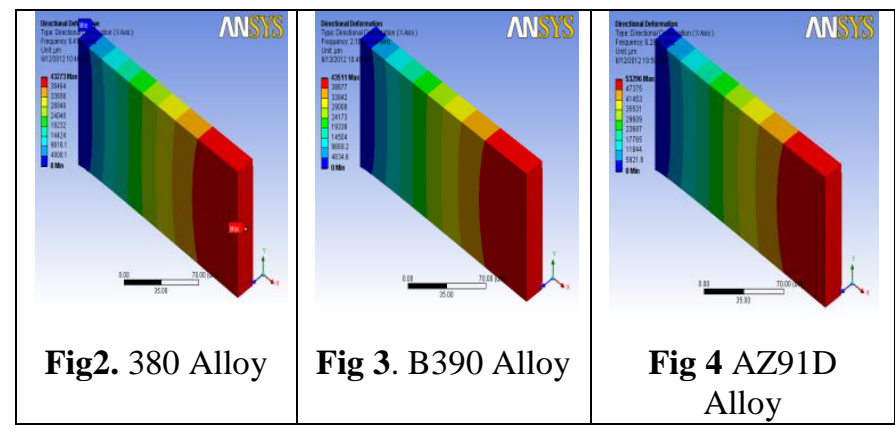

The vibration characteristics (natural frequencies and mode shapes) of a structure or a machine component are determined by carrying out modal analysis. The natural frequency and mode shapes are important parameters of vibration study.

\subsection{Harmonic Response Analysis. [3]}

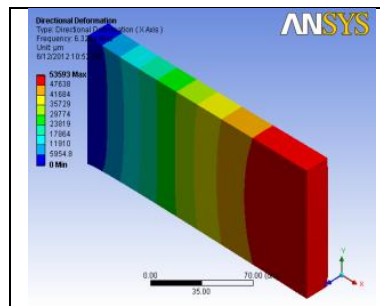

Fig 5. AM60B Alloy

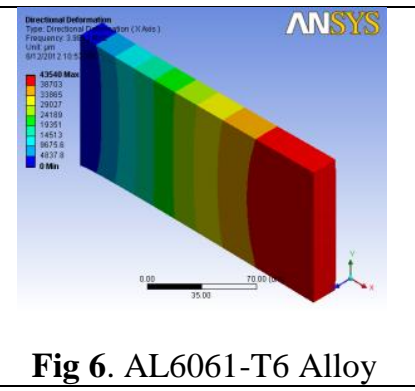

Fig 6. AL6061-T6 Alloy
In a structural system, any sustained cyclic load will produce a sustained cyclic or harmonic response. Harmonic analysis results are used to determine the steady-state response of a linear structure to loads that vary sinusoid ally (harmonically) 
with time, thus enabling you to verify whether or not your designs will successfully overcome resonance, fatigue, and other harmful effects of forced vibrations. This analysis technique calculates only the steady-state, forced vibrations of a structure. The transient vibrations, which occur at the beginning of the excitation, are not accounted for in a harmonic response analysis.

In this analysis all loads as well as the structure's response vary sinusoidally at the same frequency. The response of the structure to cyclic loads over a frequency range is plotted. The peak frequencies then observed. The corresponding displacement values rather the stress values are noted down. The various properties have been considered for the test specimen for ANSYS analysis are tabulated as shown in Table 2 .

Table 2 Mechanical Properties of Aluminium Alloys. [2] [11]

\begin{tabular}{|l|l|l|l|}
\hline Alloys & $\begin{array}{l}\text { Young's } \\
\text { modulus,Pa }\end{array}$ & $\begin{array}{l}\text { Poisson's } \\
\text { ratio }\end{array}$ & Density,kg/m3 \\
\hline A360 & $71 \times 109$ & 0.33 & 2630 \\
\hline 380 & $71 \times 109$ & 0.33 & 2740 \\
\hline B390 & $71 \times 109$ & 0.33 & 2710 \\
\hline AZ91D & $45 \times 109$ & 0.35 & 1810 \\
\hline AM60B & $45 \times 109$ & 0.35 & 1790 \\
\hline Al 6061-T6 & $27 \times 109$ & 0.35 & 2712 \\
\hline
\end{tabular}

The directional deformations of different alloys have been shown in the following Figures 2 through 6. The comparisons are given in the Table 3 .

Table 3 Alloys and Their Deformation

\begin{tabular}{|l|l|l|}
\hline Alloy & $\begin{array}{l}\text { Frequency, } \\
\mathrm{MHz}\end{array}$ & $\begin{array}{l}\text { Deformation, } \\
\mu \mathrm{m}\end{array}$ \\
\hline 380 & 6.4159 & 43273 \\
\hline B390 & 6.3915 & 43511 \\
\hline AZ91D & 6.2914 & 53296 \\
\hline AM60B & 6.3264 & 53593 \\
\hline Al6061-T6 & 5.9812 & 43540 \\
\hline
\end{tabular}

The directional deformation of each alloy considered for the study is compared and is shown in Figure 7.

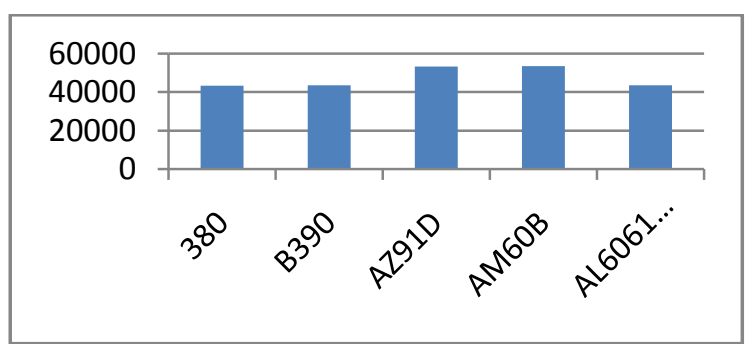

Fig 7 Directional Deformation of Different Alloys
It is observed from the Figure that the deformation of alloy 380 is minimum with a value of $43273 \mu \mathrm{m}$ and the same time the frequency of vibration is minimum as compared to the other alloys considered for the study.

\section{CONCLUSIONS}

The work presented in this paper is aimed at the study of effect of vibration characteristics of alloys. The presentation and discussion of the results of effects of vibration on the alloys. From the analysis it is concluded that as the increase of copper and silicon content in the alloys decreases deformation inversely. The boundary conditions, material properties and load are added interactively. The harmonic analysis has been made to determine frequency characteristics. The analysis program reads the data from the input file processes the data and creates the output file containing the nodal displacements and nodal stress values of different stresses. Young's Modulus and the ultimate tensile strength of the 380 alloys increase with the increase in copper and silicon content. Deformation is least in the case of 380 alloys. ANSYS results confirm the least deformation in case of 380 alloys. Hence it is recommended for low vibration applications.

\section{REFERENCES}

[1]. Aluminium extrusion company, Met Trade India ltd, www.mettradeindia.com.

[2]. Alloy Data chart-www.phbcorp.com/cms/ uploads/Alloy\%20Data-3pdf.

[3]. ANSYS 11.0 Help.

[4]. Tirupathi. R.Chandrapatla,Ashok. D. Belagundu "Introduction to finite elements in engineering".

[5]. Paper published by Prof V.V.Kuppast, S.A.Kori on "the effect of grain refiner/modifier on LM-25 and LM-26 and their stress analysis using ANSYS" ICAMDD 2005, PANAJI, GOA 13-6-DEC 2005.

[6]. R.K.Bansal, strength of materials, Laxmi Publications (P) ltd, New Delhi.2009.

[7]. Guo-cong http//dx.doi.org/10.1016/S1003-6326 (11)61291-0. Source research from sciverse hub.

[8]. R.D.Adams, Dept. of Mechanical Engineering University, Bristol. , http//dx.doi.org/10.1016// 0022- 460X (72)90560-3.

[9]. Jean-Marie Berthelot, http//dx.doi.org/ 10.1016/jcompstruct.

[10]. A Hazrati Niyari, Young Researchers Club, Ardabil Branc.h, Islamic Azad University, Ardabil, Iran. Faculty of Mechanical Engineering, Semnan University, Semnan, Iran. [11]. Yijie Zhang, The State Key Laboratory of Metal Matrix Composites of Shanghai Jiaotong University, Shanghai, 200030, PR China, http://dx.doi.org/10.1016/j.matlet.2005.06.055 